\title{
Utilisation de l'azote des fourrages verts par le mouton en croissance : influence du stade de végétation, de l'espèce fourragère, de la fertilisation azotée et de l'addition d'orge
}

\author{
Eilisabeth GRENET et C. DEMARQUILLY \\ avec la collaboration technique de J. M. Borssau, H. BousQueT, \\ Madeleine DUdiliEu, Marie JaILLER, Jacqueline Jamót et L. L'HothLiER \\ Labovatoire des Aliments \\ Centre de Recherches de Clermont-Ferrand, I.N.R.A. \\ Theix, Saint-Genès-Champanelle, 631 Io Beaumont (France)
}

\section{Résumé}

Trente-cinq échantillons de fourrages verts ont été étudiés : luzerne, ray-grass italien, ray-grass anglais, fétuque élevée et dactyle récoltés à divers stades de végétation du $\mathrm{I}^{\mathbf{e r}}$ cycle et à divers âges de repousses. Le $3^{\mathrm{e}}$ cycle de dactyle correspond à 2 taux de fertilisation azotée. Vingt-neuf des fourrages ont été distribués seuls et six, soit seuls, soit avec de l'orge qui représente dans chaque cas $23 \mathrm{p}$. ıoo de la matière sèche totale ingérée. La digestibilité, la quantité ingérée et le bilan azoté ont été mesurés sur des lots de 6 moutons âgés de 15 mois environ et pesant $40 \mathrm{~kg}$ en moyenne. La teneur en azote ammoniacal $\mathrm{du}$ jus de rumen a été déterminée avec 2 moutons supplémentaires munis d'une fistule du rumen.

La quantité d'azote retenue varie de $-0,5 \grave{a}+I 6,2 \mathrm{~g}$ par jour. Elle augmente en même temps que la quantité d'azote ingérée. Elle a été diminuée par la fertilisation azotée et n'a pas été augmentée pat la supplémentation avec de l'orge.

La quantité d'azote retenue augmente aussi en même temps que la quantité de matière organique digestible ingérée et que la digestibilité du fourrage. Elle diminue quand la teneur en cellulose brute augmente. Une meilleure estimation de la quantité d'azote retenue est obtenue en associant la quantité d'azote ingérée à la quantité de matière organique digestible ingérée. Il existe cependant des différences entre espèces végétales, les ray-grass permettant des rétentions d'azote plus élevées que les dactyles à mêmes quantités d'azote et de matière organique digestible ingérées.

La concentration moyenne journalière en azote ammoniacal du jus de rumen est très variable : de 33 à $332 \gamma / \mathrm{ml}$. Elle augmente avec la quantité d'azote ingérée. La quantité d'azote excrétée dans l'urine augmente avec la teneur en azote ammoniacal du jus de rumen. Avec les fourrages verts l'existence d'un bon équilibre entre les quantités d'azote et d'énergie apportées aux microorganismes du rumen, et absorbées dans l'intestin, permet des rétentions élevées d'azote. Les différences entre espèces fourragères sont discutées, ainsi que le peu d'intérêt du point de vue nutritionnel de la distribution d'orge en supplément de fourrages jeunes offerts à volonté. 


\section{Introduction}

La teneur en matières azotées apparemment digestibles (M.A.D.) ne rend pas bien compte chez le ruminant de la quantité d'acides aminés absorbée dans l'intestin grêle, qui représente la valeur azotée réelle des aliments. Ces acides aminés ont deux origines, alimentaire et microbienne (Chalmers et SyNGE, I954). La première dépend de la quantité d'azote ingérée par l'animal, non dégradée, dans le rumen (c'est-à-dire de la quantité d'azote ingérée et de la fermentescibilité de cet azote), la seconde essentiellement de la quantité d'énergie disponible pour la synthèse des protéines microbiennes dans le rumen, c'est-à-dire de la quantité de matière organique digestible digérée dans le rumen, du moins quand la teneur en azote fermentescible n'est pas un facteur limitant de cette synthèse protéique microbienne. En définitive, la valeur azotée réelle d'un aliment dépend de la teneur en azote et de la fermentescibilité de cet azote dans le rumen, de la quantité de matière organique digestible ingérée et du bon synchronisme entre la formation d'ammoniaque dans le rumen et la fourniture d'énergie aux microorganismes du rumen, c'est-à-dire la vitesse de digestion de la matière organique digestible.

Peu d'études ont été effectuées sur les fourrages verts. On sait cependant que la quantité d'azote retenue par l'animal en croissance, qui est une bonne estimation de la valeur azotée réelle, est élevée quand il reçoit des fourrages verts jeunes, digestibles, riches en azote, mais qu'elle diminue avec l'âge du fourrage, en même temps que la teneur en azote et en matière organique digestible (Mac Graham, I964; Du Plessis et Merve, r969; Rat'Tray et Joyce, ig69; Mac Rae et Ulyatr, I974 et Hume et Purser, I974). Cependant, à même quantité d'azote et (ou) de matière organique digestible ingérée, il peut exister des différences entre fourrages, comme l'ont montré JoycE et NEWTH (I967) et RATTRAY et JoycE (I969) en mesurant la rétention azotée, et Mac RAE et ULYATT (I974) en mesurant la quantité d'acides aminés absorbée dans 1'intestin grêle. Elles peuvent résulter, suivant les fourrages, de différences dans la fermentescibilité de l'azote dans le rumen, ou dans la vitesse de digestion de la matière organique digestible dans le rumen par suite de modifications dues à l'espèce, au stade de végétation ou à la fertilisation, azotée notamment. Cette dernière augmente en effet la teneur en azote $\mathrm{du}$ fourrage et diminue la teneur en glucides solubles et le rapport azote protéique sur azote total, mais ne modifie pas, ou peu, la digestibilité de la matière organique (WAITE, I958; Nowakowsky, I962; CAMERon, I966; REID, Jung et Murray, ig66; Demarquiliy, I970; Huguet et Gillet, I973).

Aussi avons-nous étudié comment varie la quantité d'azote retenue par le mouton en croissance recevant des fourrages verts en relation avec la concentration en azote ammoniacal du jus de rumen, suivant la nature du fourrage, sa digestibilité et la fertilisation azotée reçue, et si, éventuellement, elle peut être augmentée par une complémentation en énergie rapidement fermentescible (céréales). Les réstultats rapportés ici ont servi de base pour mesurer l'influence de la conservation des fourrages par ensilage sur la rétention azotée, qui fera l'objet d'une publication ultérieure. 


\section{Matériel et méthodes}

\section{Fourrages étudiés}

Trente-cinq échantillons de fourrages verts ont été étudiés au total provenant de 5 prairies de Theix, à $800 \mathrm{~m}$ d'altitude (luzerne, ray-grass italien, ray-grass anglais, fétuque élevée et dactyle) récoltées à divers stades de végétation du I ${ }^{\mathrm{er}}$ cycle et à divers âges de repousses, et d'une prairie de luzerne en plaine (domaine du C.N.E.E.M.A. à Montoldre) récoltée au $\mathrm{I}^{\mathrm{er}}$ et au $2^{\mathrm{e}}$ cycle ( $30 \mathrm{j}$. de repousses) (tabl. I et 2).

Le $3^{\mathrm{e}}$ cycle de dactyle correspond à 2 taux de fertilisation azotée, 33,5 unités d'azote et Ioo unités d'azote à l'hectare respectivement ont été appliquées sur chacune des deux moitiés de la parcelle après la fauche du $2^{\mathrm{e}}$ cycle. Trois comparaisons ont été effectuées.

Vingt-neuf des fourrages ont été distribués seuls et six, soit seuls, soit avec de 1'orge représentant dans chaque cas 23 p. roo de la matière sèche totale ingérée. Qu'ils aient été distribués seuls ou avec de l'orge, les fourrages ont toujours été été offerts à volonté (ro $\mathrm{F}$. roo de refus).

\section{Mesures}

La digestibilité, la quantité ingérée et le bilan azoté ont été mesurés sur des lots de 6 moutons mâles castrés de race Texel, âgés de I 2 mois environ (l'âge des moutons variait entre 5 et $\mathrm{I} 6$ mois suivant les lots) et pesant $50 \mathrm{~kg}$ en moyenne (entre 30 et $67 \mathrm{~kg}$ ) au début des mesures (le poids d'un adulte est de 80-roo $\mathrm{kg}$ ). Nous disposions d'un lot de moutons pour chaque espèce fourragère. Les animaux étaient alimentés avec le fourrage vert étudié pendant une durée minimum de 3 semaines avant la période de mesure qui était de 6 jours.

Les moutons maintenus en cage à métabolisme équipée d'une goulotte pour la récolte de l'urine, ont été alimentés à volonté en 2 repas par jour à 8 h et I 6 h 30 . L'herbe nécessaire aux animaux était fauchée chaque matin, exception faite de la luzerne cultivée à Montoldre qui était congelée et stockée en chambre froide. L'orge a été distribuée en 2 repas égaux avant chaque distribution de fourrage vert.

Les mestrres de digestibilité et d'ingestibilité ont été réalisées selon la méthode de Demarquiliy (DEMARQuiliy et Weiss, I970).

L'urine, récoltée dans des jerricans contenant de 50 à too $\mathrm{ml}$ de solution d'acide sulfurique R.P. à 30 p. Ioo, était pesée chaque jour et une quantité aliquote conservée à $+4^{\circ} \mathrm{C}$ jusqu'à $1^{\prime}$ issue de la période de mesure.

Nous avons prélevé du jus de rumen sur 2 moutons supplémentaires, munis d'une fistule du rumen, juste avant la distribution du repas du matin puis $I, 2$, $3,4,6$ et 8 heures après, et durant 2 jours consécutifs lors de chaque période de mesure. Ces animaux étaient alimentés à volonté comme les moutons en lots et leur consommation ramenée au $\mathrm{kg}$ de poids métabolique était du même ordre de grandeur.

\section{Analyses}

Les échantillons représentatifs de 1'herbe et de l'orge offertes, de l'herbe refusée et des fèces correspondant à chaque période de mesure ont été analysés pour déterminer leur teneur en cendres, en cellulose brute et en azote. Sur les 


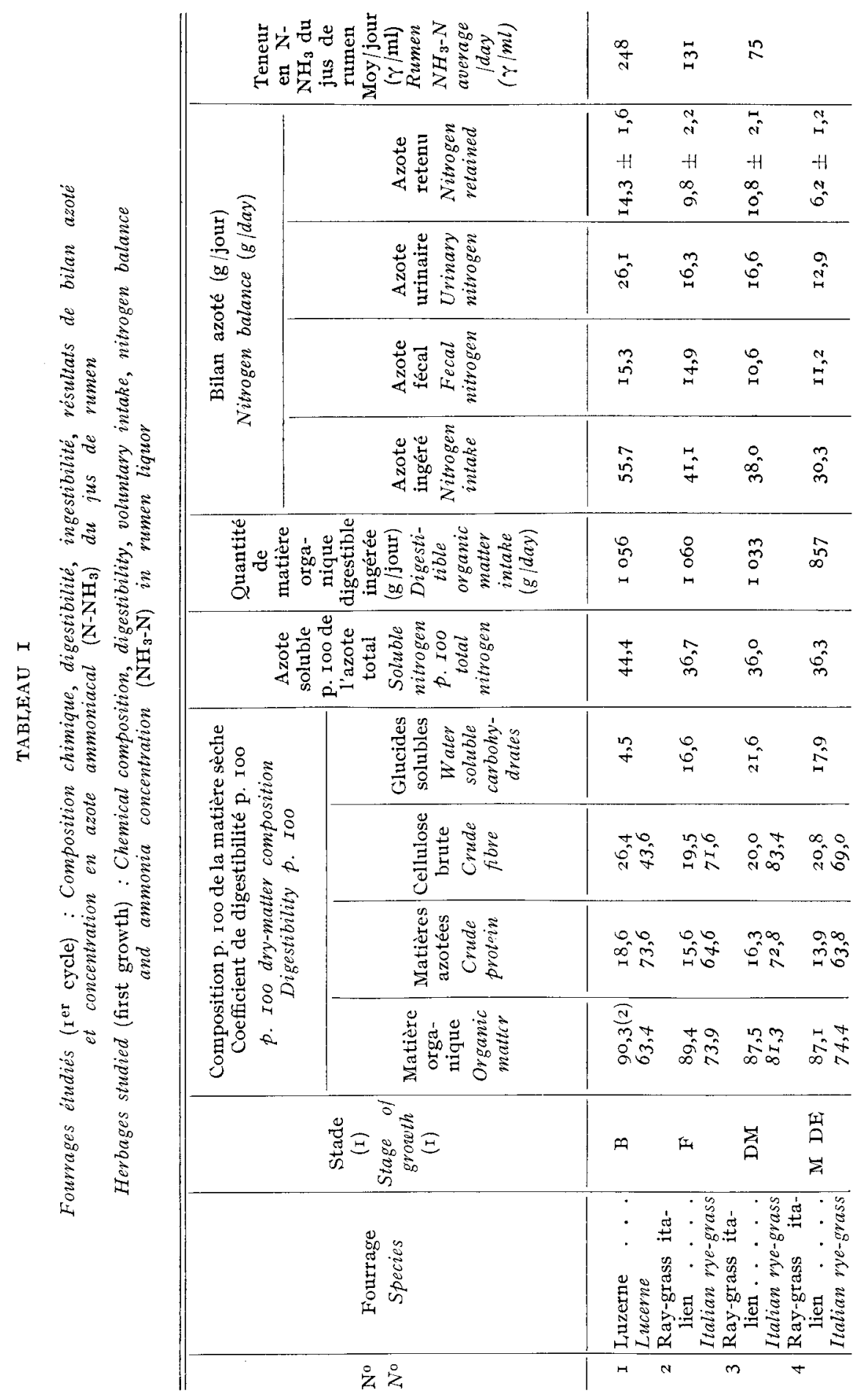




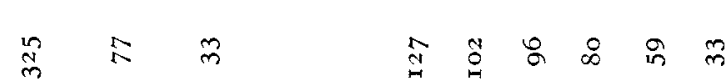

\begin{tabular}{|c|c|c|c|c|c|c|c|c|c|c|}
\hline $\begin{array}{l}0 \\
\text { in }\end{array}$ & $\stackrel{+}{H}$ & $\vec{H}$ & $\hat{0}$ & $\dot{N}$ & $\stackrel{\infty}{\stackrel{\infty}{\sharp}}$ & $\hat{n}$ & $0^{2}$ & $\begin{array}{l}0 \\
0\end{array}$ & $\tilde{c}_{0}^{\prime}$ & $0^{n}$ \\
\hline$H$ & +1 & +4 & +1 & $H$ & $H$ & $-H$ & $H$ & $H$ & $H$ & +1 \\
\hline$\hat{\sigma}^{1}$ & $\begin{array}{l}0_{0}^{\prime} \\
0^{2}\end{array}$ & $\stackrel{\infty}{+}$ & $\stackrel{0}{+}$ & $\stackrel{\infty}{\infty}$ & $H_{n}$ & $\hat{n}$ & $\stackrel{n}{r}$ & $\begin{array}{l}0 \\
0^{n}\end{array}$ & $n^{n}$ & $0^{\circ}$ \\
\hline $\begin{array}{c}0 \\
\text { on } \\
\text { in }\end{array}$ & $\dot{0}_{0}$ & $\stackrel{\infty}{N}$ & $\underset{H}{g}$ & $\begin{array}{l}0 \\
0 \\
0\end{array}$ & $\stackrel{2}{2}^{2}$ & $\hat{m}$ & Oे & $\begin{array}{l}\infty \\
\hat{\sigma}\end{array}$ & $\begin{array}{c}C_{\infty}^{\prime} \\
\infty\end{array}$ & î \\
\hline
\end{tabular}

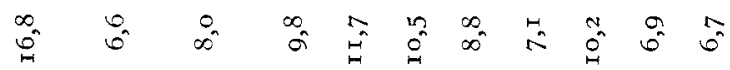

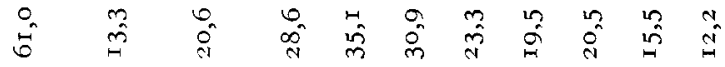

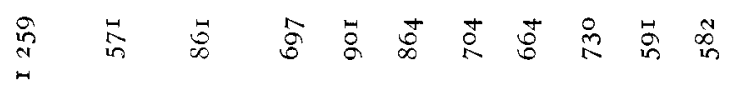

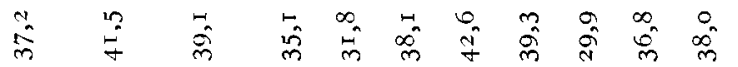

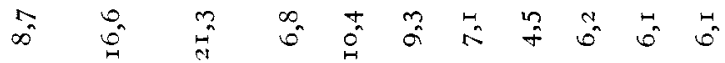

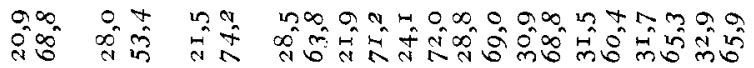

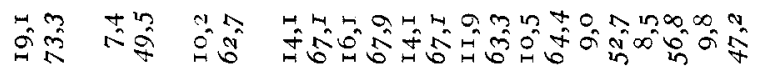

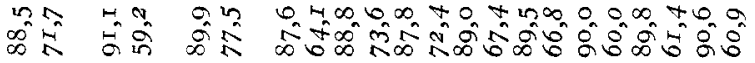

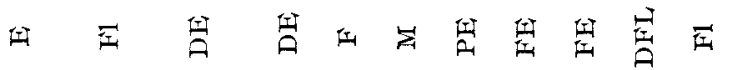
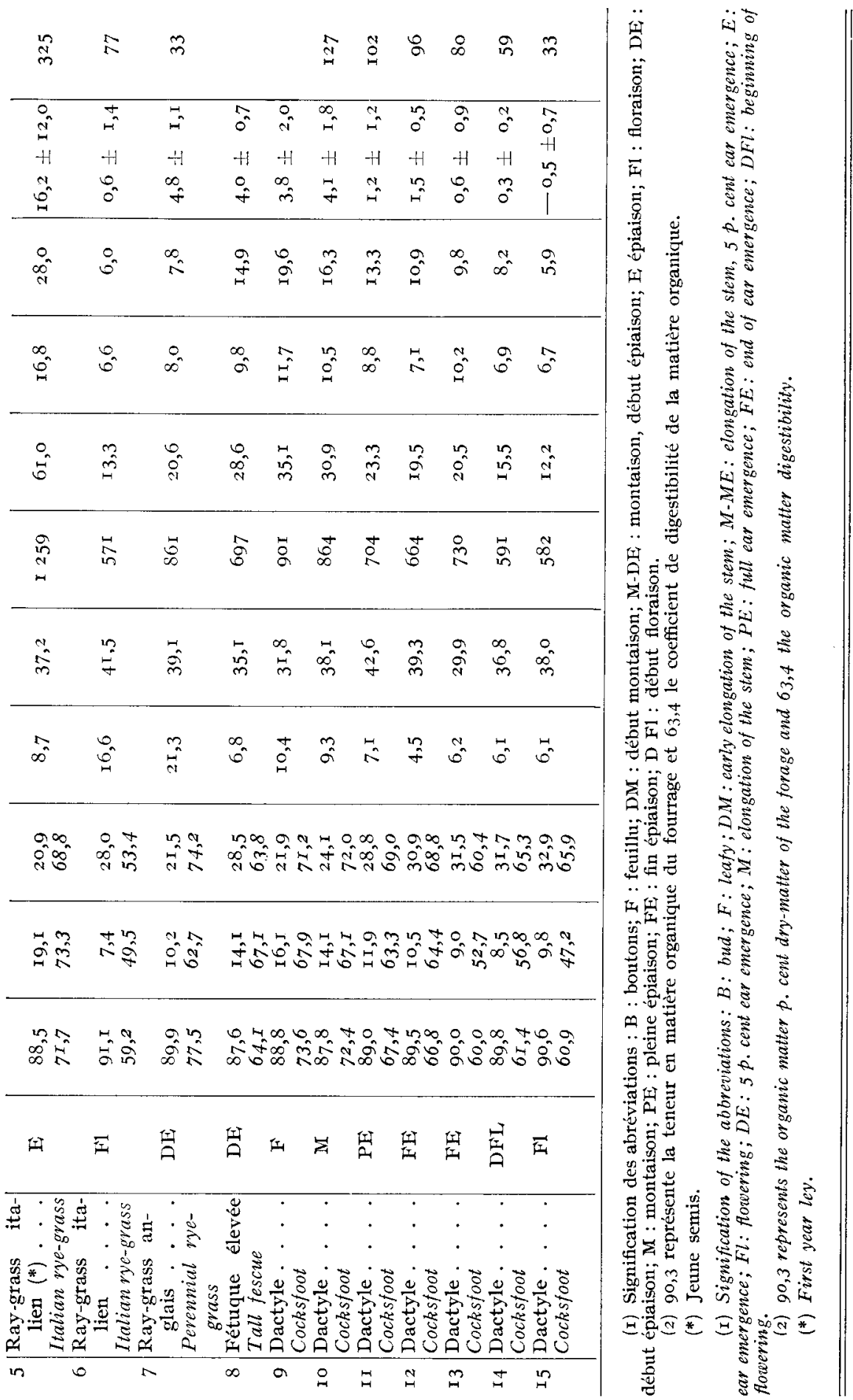
E. GRENET, C. DEMARQUII, Y

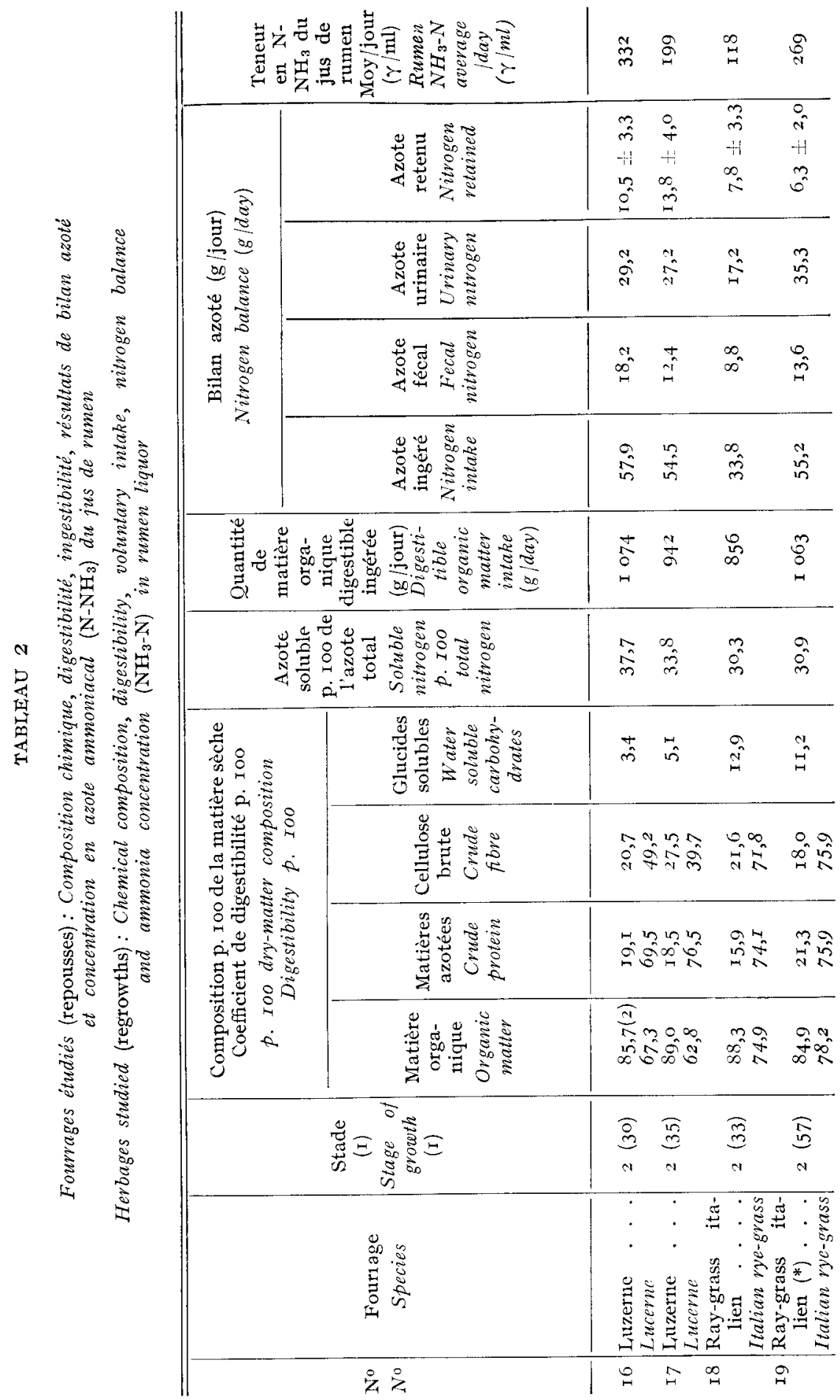




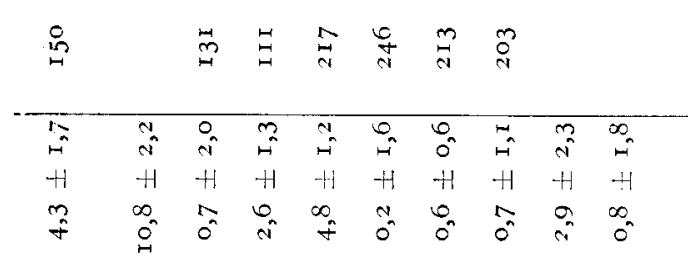

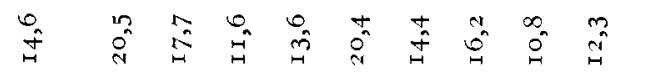

$\hat{0} \quad \begin{aligned} & 0 \\ & \hat{1}\end{aligned}$

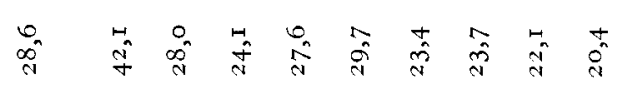

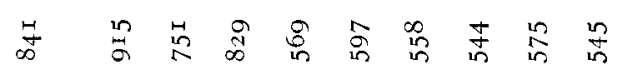

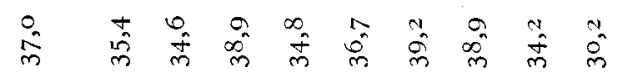

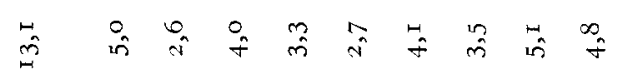

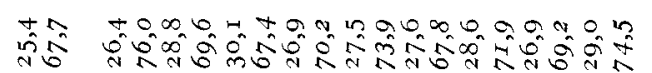

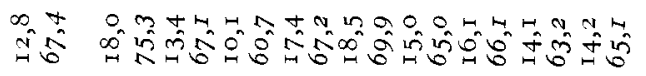

H人

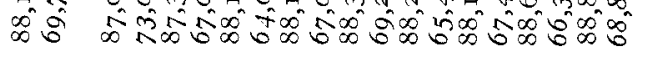

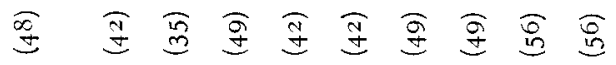

$$
\begin{aligned}
& \text { a a व } a \mathrm{~m} m \mathrm{~m} m
\end{aligned}
$$

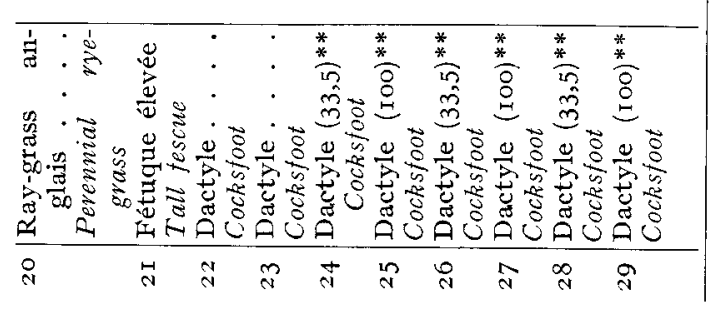


premiers échantillons les teneurs en azote et en glucides solubles dans ?'eau a $40^{\circ} \mathrm{C}$ ont été mesurées : ces derniers ont été estimés par le pouvoir réducteur (Somogyi, I952) de l'extrait aqueux. Les échantillons moyens individuels d'urine ont été analysés pour déterminer leur teneur en azote.

Les échantillons de jus de rumen ont été conservés à $-{ }^{\circ} 5^{\circ} \mathrm{C}$ après addition de chlorure de sodium à $\mathrm{I} 2,5 \mathrm{p}$. Ioo dans la proportion de I volume de jus de rumen pour 4 volumes de solution jusqu'au moment de la détermination de leur teneur en azote ammoniacal à l'auto-analyseur Technicon.

\section{Résultats}

\section{Fourrages verts distribués seuls}

La digestibilité de la matière organique, des matières azotées, de la cellulose brute et l'ingestibilité des échantillons étudiés varient dans des proportions importantes, respectivement de 59,2 à $8 \mathrm{I}, 3$ p. Ioo, 47,2 à 76,5 p. I00,39,8 à 83,4 p. IoO et de 544 à I $259 \mathrm{~g}$ de matière organique digestible par jour (tabl. I et 2). Ces variations traduisent essentiellement les différences liées au stade de végétation des fourrages puisque celui-ci varie du stade feuillu au stade floraison. Elles traduisent aussi, mais à un moindre degré les différences entre espèces végétales : pour une même digestibilité de la matière organique, la cellulose brute de la luzerne est moins digestible mais l'ingestibilité de ce fourrage est plus élevée que celle des graminées.

La quantité d'azote ingérée $(x i)$ s'échelonne entre $\mathrm{I} 2,2$ et $6 \mathrm{I} g$ par jour. Les quantités d'azote excrétées dans les fèces (Y $f$ ) et dans l'urine (Yu) et la quantité d'azote retenue $(\mathrm{Y} r)$ varient respectivement de 6,6 à $\mathrm{I} 8,2$; de 5,9 à 35,3 et de - 0,5 à I6,2 g par jour (tabl. I et 2); elles sont plus élevées pour les luzernes que pour les graminées et diminuent quand la maturité du fourrage augmente pour le ray-grass italien et le dactyle de er $^{\text {er }}$ cycle, la quantité d'azote retenue devenant même négative pour le dactyle à la floraison (la quantité d'azote retenue très élevée et très variable : $\mathrm{I} 6,2 \mathrm{~g} \pm \mathrm{I} 2,0$ obtenue pour l'échantillon $\mathrm{n}^{\circ} 5$ est vraisemblablement due à une période d'adaptation trop courte des animaux qui, en pleine période de sécheresse, sont passés d'un régime de fourrages pauvres à un régime de fourrage vert jeune et très digestible). Elles sont étroitement liées à la quantité d'azote ingérée comme le montrent les relations suivantes calculées pour tous les échantillons $(n=26)$ ou pour les graminées seules $(n=23)$ :

$$
\begin{array}{llll}
\mathrm{Y} f=4,2 \mathrm{I}+0, \mathrm{I} 9 x i \pm \mathrm{I}, 26 & r=0,9 \mathrm{I} & n=26 \\
\mathrm{Y} f=4,36+0, \mathrm{I} 9 x i \pm \mathrm{I}, 09 & r=0,9 \mathrm{I} & n=23 \\
\mathrm{Y} u=0, \mathrm{I} 3+0,50 x i \pm 2,37 & r=0,95 & n=26 \\
\mathrm{Y} u=-0,24+0,5 \mathrm{I} x i \pm 2,50 & r=0,93 & n=23 \\
\mathrm{Y} r=-4,25+0,30 x i \pm 2,23 & r=0,89 & n=26 \\
\mathrm{Y} r=-4, \mathrm{I} 5+0,29 x i \pm 2,25 & r=0,85 & n=23
\end{array}
$$

La quantité d'azote retenue exprimée en p. Ioo de l'azote ingéré varie de - 4, I à 28,4 p. Ioo, et exprimée en p. Ioo de l'azote digestible de - 9, I à 39,4 p. Ioo. Elle diminue avec 1'âge du fourrage au cours du $x^{\text {er }}$ cycle de croissance et est un peu plus élevée pour les repousses que pour les premiers cycles en moyenne.

L'augmentation de la fertilisation azotée de 33,5 à Ioo $\mathrm{kg}$ d'azote par ha a 
légèrement accru la teneur en azote du dactyle, ainsi que la digestibilité de la matière organique, des matières azotées et de la cellulose brute (de 2 à 4 points) mais a diminué de $4,5 \mathrm{p}$. Ioo l'ingestibilité. La quantité d'azote ingérée a été peu modifiée, la quantité d'azote excrétée dans les fèces a baissé, mais, en revanche, la quantité d'azote excrétée dans l'urine a très nettement augmenté, de sorte que la quantité d'azote retenue a diminué; en moyenne cette dernière est passée de 2,77 à 0,10 g par jour (tabl. 2).

\section{Fourrages distribués avec de l'orge}

La distribution d'orge avec les fourrages verts a un effet variable sur la digestibilité de la matière organique de la ration (fig. I). Elle ne l'augmente pas pour les fourrages dont la digestibilité de la matière organique est élevée, supérieure à $70 \mathrm{p}$. Ioo, elle a même tendance à la diminuer, tandis que pour les fourrages dont la digestibilité est inférieure à $70 \mathrm{p}$. Ioo elle l'augmente jusqu'à plus de 6 points pour le ray-grass italien à la floraison. L'orge diminue la digestibilité des matières azotées de la luzerne, diminue la digestibilité de la cellulose brute de la luzerne et des ray-grass; elle modifie peu la quantité de matière organique digestible ingérée ou l'augmente un peu pour deux ray-grass du I ${ }^{\text {er }}$ cycle et pour la luzerne (tabl. 3 ).

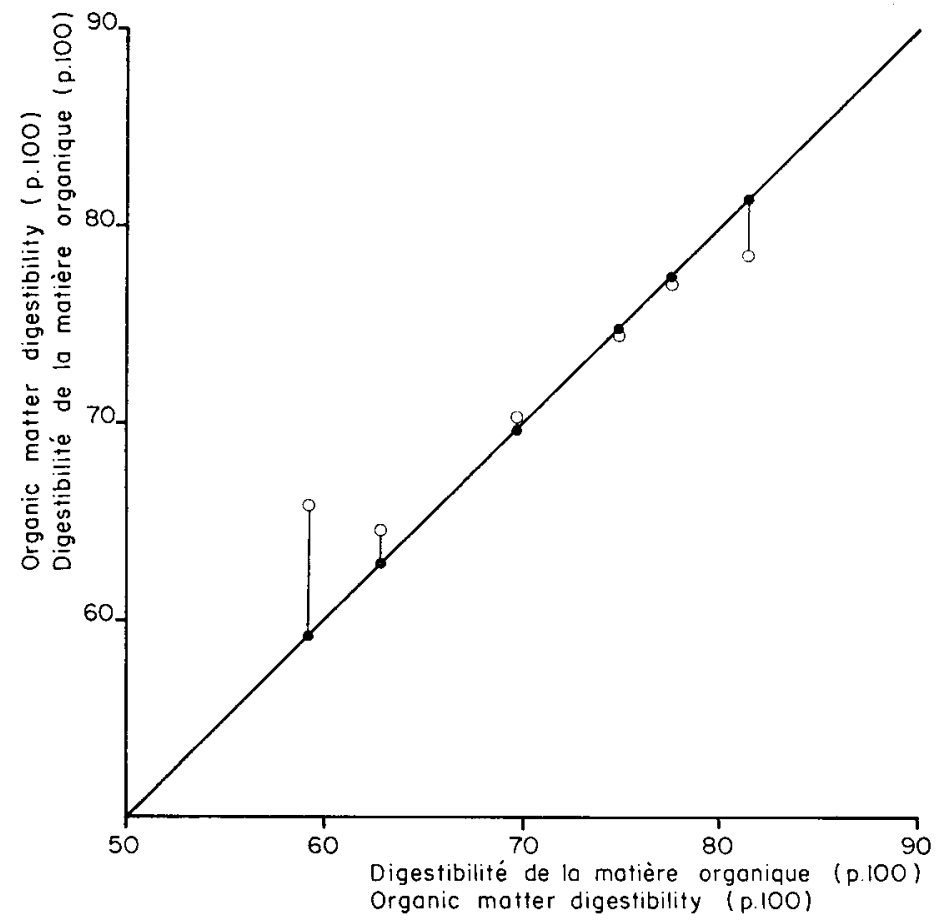

FIG. I. - Influence de la supplémentation avec de l'orge sur la digestibilité de la matière organique des fourrages verts

Effect of supplement of bavley on organic matter digestibility of fresh herbage

- Fourrage seul Hevbage
- Fourrage + orge Herbage + barley 
E. GRENET, C. DEMARQUILLY

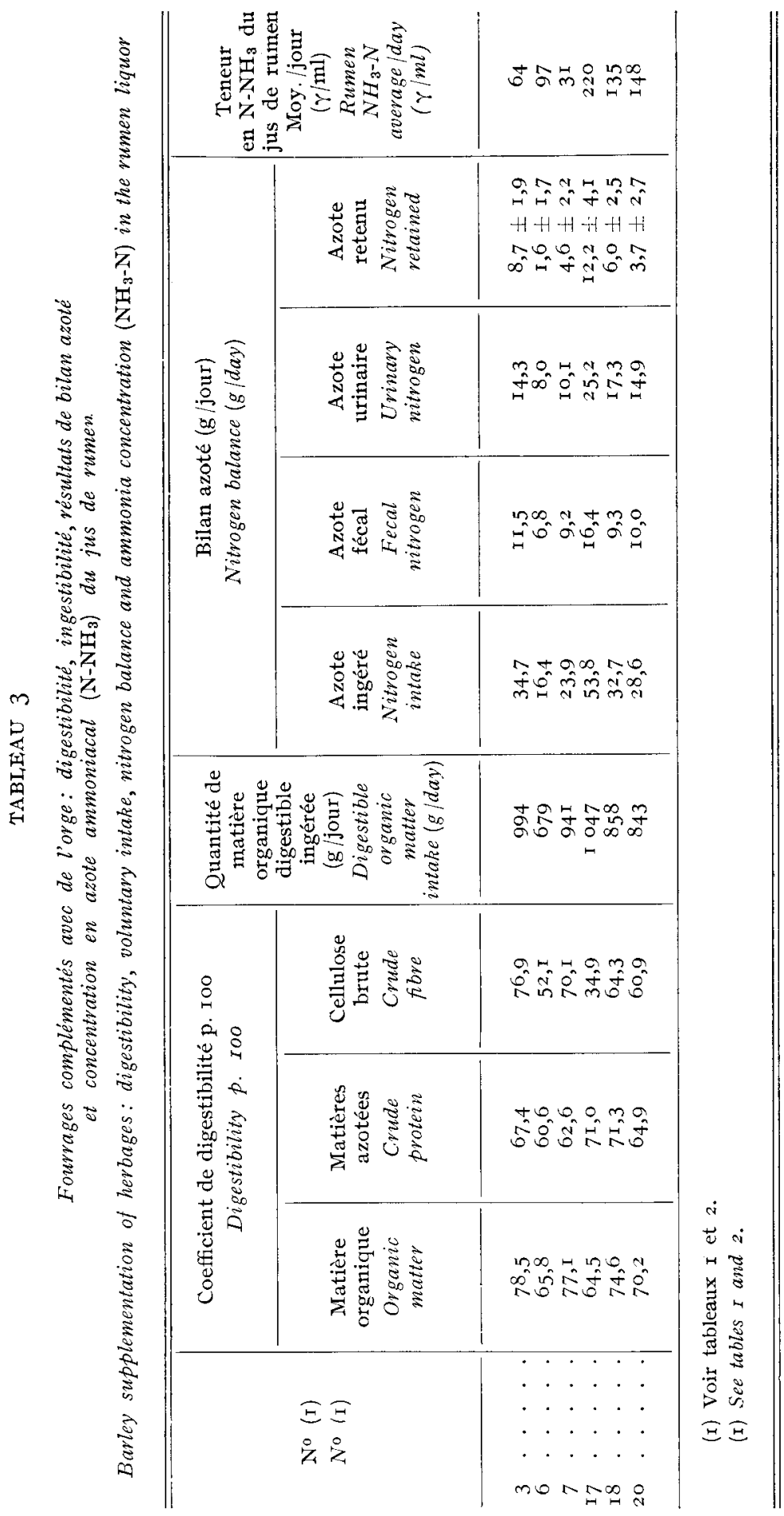




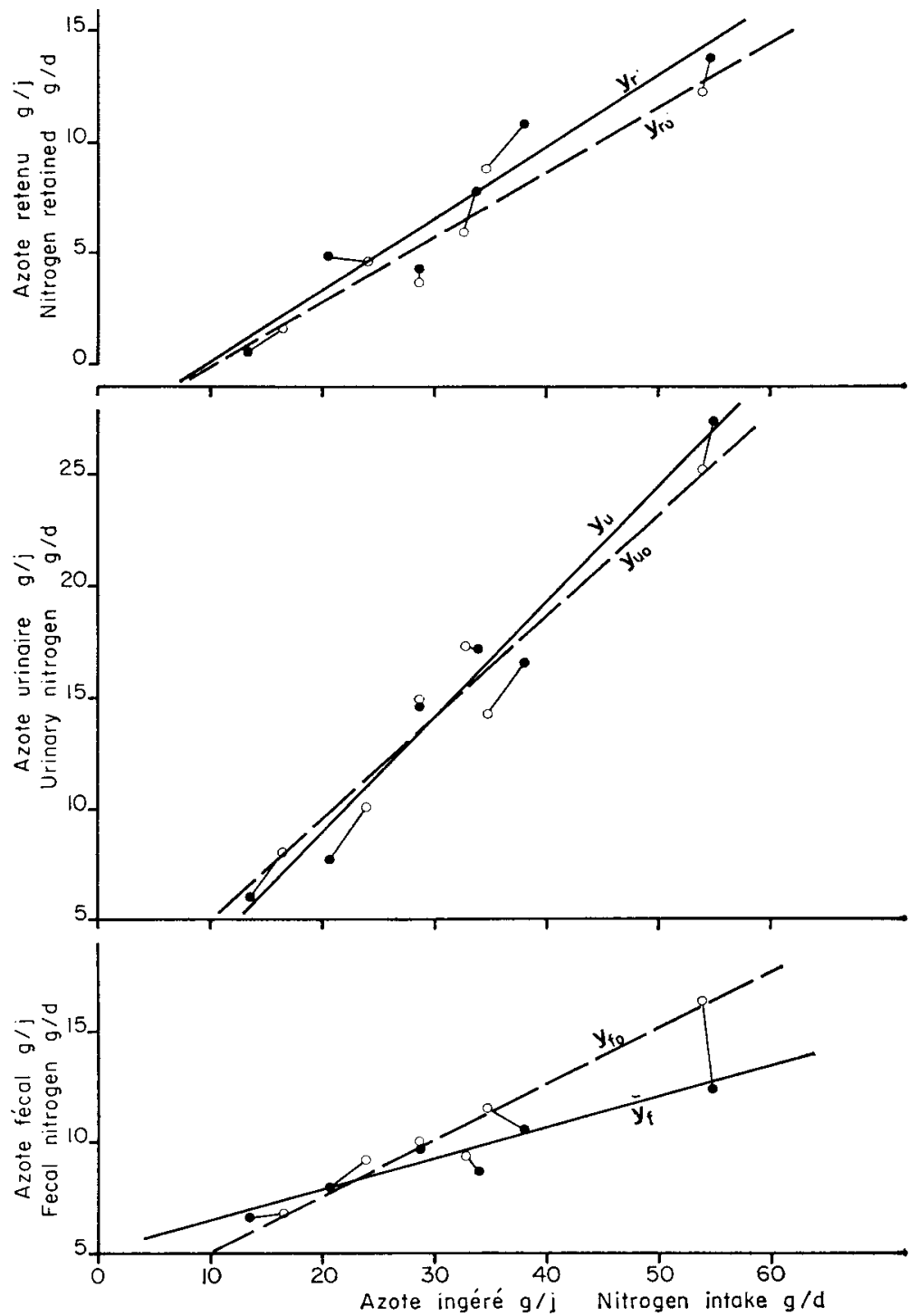

FIG. 2. - Influence de la quantité d'azote ingérée pour les fourrages distribués seuls ou avec orge ( $\mathrm{xi}$ et $\mathrm{xi}_{\mathrm{o}}$ ) sur la quantité d'azote fecal (Yf et $\mathrm{Yf} \mathrm{f}_{0}$ ),

la quantité d'azote urinaive ( $\mathrm{Yu}$ et $\mathrm{Yu}_{0}$ ) et la quantité d'azote retenue (Yr et Yro)

Effect of level of nitrogen intake for herbages without or with a supplement of barley ( $\mathrm{xi}$ and $\mathrm{xi}$ ) on fecal nitrogen ( $\mathrm{Yf}$ and $\mathrm{Yf}_{0}$ ), urinary nitrogen ( $\mathrm{Yu}$ and $\mathrm{Yu}_{0}$ ) and nitrogen retained ( $\mathrm{Yr}$ and $\mathrm{Yr}_{0}$ )

- Fourrage seul Herbage o Fourrage + orge Herbage + barley

$$
\begin{aligned}
& \text { Yf }=+5.07+0.14 \times i \pm 0.62 \\
& Y f_{0}=+2.62+0.25 \mathrm{xio}_{0}+0.84 \\
& \mathrm{Yu}=-\mathrm{I} .5 \mathrm{O}+0.52 \mathrm{xi} \pm \mathrm{I} .4 \mathrm{I} \\
& Y u_{0}=+0.32+0.46 \mathrm{x}_{\mathrm{i} 0} \pm \mathrm{I} .67 \\
& \mathrm{Yr}=-3.05+0.32 \mathrm{xi} \pm \mathrm{I} .45 \\
& \mathrm{Yr}_{\mathbf{0}}=-2.96+0.29 \mathrm{x}_{\mathbf{i} 0} \pm \mathrm{I} .23 \\
& r=0.96 \\
& r=0.93 \\
& r= \pm 0.99 \\
& \gamma=0.97 \\
& r=0.95 \\
& r=0.96
\end{aligned}
$$


Les quantités d'azote ingérées sont relativement peu modifiées. Les relations entre, d'une part, les quantités d'azote excrétées dans les fèces et dans l'urine ou la quantité d'azote retenue et, d'autre part, la quantité d'azote ingérée exprimée en $\mathrm{g}$ par jour, pour les fourrages seuls et les fourrages avec orge sont représentées sur la figure 2. Les pentes des deux droites de régression de la quantité d'azote fécal excrétée (Yfo et $\mathrm{Y} f$ ) en fonction de la quantité d'azote ingérée (xio et $x i$ ) pour les fourrages avec ou sans orge, sont significativement différentes l'une de l'autre : l'addition d'orge à ces fourrages verts a donc entraîné une augmentation significative de la quantité d'azote fécal à même quantité d'azote ingérée. Il en est de même si la quantité d'azote fécal est rapportée à la quantité de matière sèche ingérée $(\mathrm{Y} f \mathrm{I}$ et $\mathrm{Y} f \mathrm{I})$ :

$$
\begin{array}{lll}
\text { Y } \mathrm{I}=0,60+0,003 x i \pm 0,02 & r=0,87 & n=6 \\
\text { Yfor }=0,50+0,008 x i o \pm 0,03 & r=0,96 & n=6
\end{array}
$$

En revanche, les autres droites de régression liant la quantité d'azote urinaire our la quantité d'azote retenue à la quantité d'azote ingérée ne sont pas signifi. cativement différentes que le fourrage soit distribué seul ou avec orge. Les modifications non significatives de la quantité d'azote retenue sont donc dues uniquement aux variations de la quantité d'azote ingérée consécutives à l'addition d'orge.

\begin{tabular}{|c|c|c|c|c|c|c|c|c|}
\hline \multirow[t]{2}{*}{$x_{1}, x_{2}, x_{3}$} & \multicolumn{6}{|c|}{$\begin{array}{l}26 \text { graminées } \\
26 \text { grasses }\end{array}$} & \multicolumn{2}{|c|}{$\begin{array}{l}26 \text { graminée } \\
26 \text { grasses }\end{array}$} \\
\hline & $a$ & $b_{1}$ & $b_{2}$ & $b_{3}$ & Syx & $\begin{array}{lll}\gamma & \text { olf } & \mathrm{R}\end{array}$ & $a$ & $b_{1}$ \\
\hline Dig MO (I) & $-29,4$ & $0,4^{8}$ & & & 3,2 & $0,67(* *)$ & - 16,9 & 0,32 \\
\hline $\mathrm{CB}(2)$ & 23,3 & $-0,74$ & & & 2,8 & $-0,75\left(^{* *}\right)$ & 23,6 & 0,72 \\
\hline MODI (3) & - IO,4 & I 8,75 & & & 2,2 & $0,86(* *)$ & 一 $\mathrm{Ir}, 7$ & 20,92 \\
\hline $\operatorname{NTI}(4) \cdot \cdot \cdot \cdot$ & $-4,7$ & 0,30 & & & 2,4 & $0,83(* *)$ & $-4,8$ & $0,3 \mathrm{r}$ \\
\hline Dig MO, NTI . . & -I $3, \mathrm{I}$ & $0, I_{4}$ & 0,25 & & 2,3 & $0,84(* *)$ & $-8, \mathrm{I}$ & 0,05 \\
\hline CB, NTI . . & $: 4,8$ & $-0,28$ & 0,22 & & 2,3 & $0,85\left(^{* *}\right)$ & - I,5 & $\ldots 0,10$ \\
\hline MODI, NTI . & $-9,1$ & 12,15 & $0, \mathrm{I} 3$ & & $2, \mathrm{I}$ & $0,88(* *)$ & $-8,8$ & 9,84 \\
\hline Dig MO, MODI, NTI & - rr,9 & 0,05 & I I, 42 & 0,12 & $2, \mathrm{I}$ & $0,88(* *)$ & $-6,5$ & $\ldots o, 0_{4}$ \\
\hline CB, MODI, NTI & $-4,6$ & $-0,1^{2}$ & 10,87 & $0, \mathbf{I} \mathbf{I}$ & $2, \mathrm{I}$ & $0,88(* *)$ & $-\mathrm{II}, 4$ & 0,07 \\
\hline MODI, NTI, GS (5) & $-8,0$ & 6,95 & 0,19 & 0,14 & 2,0 & $0,89(* *)$ & $-7,8$ & 4,49 \\
\hline
\end{tabular}

TABLEAU

Liaisons entre la quantité d'azote retenue

Relations between nitrogen retained

(r) Digestibilité de la matière organique. en p. roo.

(2) Teneur en cellulose brite $p$. cent de la matière seche.

(3) Quantité de matière organique digestible ingérée en $\mathrm{kg} /$ jour.

(4) Quantité d'azote ingérée en $\mathrm{g} /$ jour.

(5) Teneur en glucides solubles p. cent de la matic̀re sèche.

NS $=$ non significatif.

(**) Significatif $\quad P \Leftarrow$ o,or. 
Liaisons entre la quantité d'azote retenue, la composition chimique et la valeur alimentaire des fourrages

La quantité d'azote retenue (NR) exprimée en $g / j o u r$, est en liaison positive très étroite, nous l'avons $\mathrm{vu}$, avec la quantité d'azote ingérée (NI) elle-même exprimée en $\mathrm{g} / \mathrm{jour}$, mais elle augmente également en même temps que la quantité de matière organique digestible ingérée (MODI en $\mathrm{g} / \mathrm{jour}$ ) et que la digestibilité du fourrage. Mais la relation avec cette dernière n'est pas significative quand on ajoute les 3 luzernes aux graminées. En revanche, la quantité d'azote retenue diminue quand la teneur en cellulose brute augmente (tabl. 4).

En prenant en compte une deuxième variable, en plus de la quantité d'azote ingérée, on améliore un peu les liaisons obtenues, la meilleure étant celle avec la quantité de matière organique digestible ingérée $(\mathrm{R}=0,88$ ou 0,90 suivant que $n=23$ ou 26 ). Si toutes les variables sont exprimées en $\mathrm{g}$ par $\mathrm{kg}$ de poids métabolique $(\mathrm{P} 0,75)$ afin de pouvoir comparer des moutons de poids différent, on obtient la relation suivante pour les 23 graminées + les 3 luzernes :

$$
\mathrm{NR}=-0,53+0,2 \mathrm{I} \mathrm{NI}+\text { o,oro MODI } \mathrm{R}=0,90
$$

exprimée en gljour et divers facteurs (g/day) and various factors

+3 luzernes

+3 lucernes
26 graminées + 3 luzernes + 6 " herbe + orge " 26 grasses + 3 lucernes +6 "herbage + barley"

\begin{tabular}{|c|c|c|c|c|c|c|c|c|c|}
\hline$b_{2}$ & $b_{3}$ & $\begin{array}{l}\text { Syx } \\
4,6 \\
3,9 \\
2,5 \\
2,4\end{array}$ & $\begin{array}{r}r \text { ou } \mathrm{R} \\
0,37 \mathrm{~N} . \mathrm{S} . \\
-0,62\left(^{* *}\right) \\
0,86\left(^{* *}\right) \\
0,88(* *)\end{array}$ & $\begin{array}{c}a \\
-\mathrm{I} 3,4 \\
\text { I } 9,4 \\
-\mathrm{I} \mathrm{I}, 9 \\
-4,6\end{array}$ & $\begin{array}{c}b_{1} \\
0,27 \\
-0,57 \\
20,94 \\
0,31\end{array}$ & $b_{2}$ & $b_{3}$ & $\begin{array}{l}\text { Syx } \\
4,5 \\
3,9 \\
2,4 \\
2,2\end{array}$ & $\begin{array}{r}r \text { ou R } \\
0,33 \text { N.S. } \\
-0,55\left(^{* *}\right) \\
0,86\left(^{* *}\right) \\
0,88\left(^{* *}\right)\end{array}$ \\
\hline $\begin{array}{l}0,30 \\
0,29 \\
0,19\end{array}$ & & $\begin{array}{l}2,4 \\
2,4 \\
2,2\end{array}$ & $\begin{array}{l}0,88(* *) \\
0,88(* *) \\
0,90(* *)\end{array}$ & $\begin{array}{l}-9,7 \\
-0, \mathbf{I} \\
-8,9\end{array}$ & $\begin{array}{r}0,08 \\
0,15 \\
9,99\end{array}$ & $\begin{array}{l}0,30 \\
0,28 \\
0,19\end{array}$ & & $\begin{array}{l}2,2 \\
2,2 \\
2,0\end{array}$ & $\begin{array}{l}0,89\left(^{* *}\right) \\
0,89\left(^{* *}\right) \\
0,91\left(^{* *}\right)\end{array}$ \\
\hline $\begin{array}{r}10,8 \text { I } \\
\text { I } 0,86 \\
0,25\end{array}$ & $\begin{array}{l}0,18 \\
0,19 \\
0,14\end{array}$ & $\begin{array}{l}2,2 \\
2,2 \\
2,1\end{array}$ & $\begin{array}{l}0,90(* *) \\
0,90(* *) \\
0,9 I(* *)\end{array}$ & $\begin{array}{r}-7, \mathrm{I} \\
-\mathrm{I} 0,2 \\
-7,4\end{array}$ & $\begin{array}{r}0,03 \\
0,03 \\
4,20\end{array}$ & $\begin{array}{c}10,95 \\
10,71 \\
0,26\end{array}$ & $\begin{array}{l}0, \mathrm{I} 8 \\
0, \mathrm{I} 8 \\
0, \mathrm{I} 4\end{array}$ & $\begin{array}{l}2,0 \\
2,0 \\
1,9\end{array}$ & $\begin{array}{l}0,9 \mathrm{I}\left({ }^{* *}\right) \\
0,9 \mathrm{I}(* *) \\
0,92(* *)\end{array}$ \\
\hline
\end{tabular}

(I) Organic matter digestibility.

(2) Crude fibre content $p$. cent dry matter.

(3) Digestible organic matter intake, kg/day.

(4) Nitrogen intake, g/day.

(5) Water-soluble carbohydrates p. cent dry matter.

n.s. : non significant.

(**) Significant $\quad P \leqslant$ o,or. 
Cette relation montre qu'un mouton à jeun doit perdre de 1'ordre de $0,53 \mathrm{~g}$ d'azote par $\mathrm{kg}$ de poids métabolique et qu'il fixe quand il reçoit des fourrages verts en moyenne $0,2 \mathrm{~g}$ d'azote par $\mathrm{g}$ d'azote ingéré et Io g d'azote par kg de matière organique digestible ingéré.

Cependant, il existe des différences entre les espèces végétales, en particulier entre les ray-grass ( + deux fétuques) et les dactyles : pour une même quantité d'azote et de matière organique digestible ingérée, les premiers permettent une rétention d'azote beaucoup plus importante que les seconds. Les équations s'écrivent, toutes les variables étant exprimées en $\mathrm{g}$ par $\mathrm{kg}$ de poids métabolique (P 0,75$)$ :

$$
\begin{array}{cc}
\mathrm{NR}=-0,5 \mathrm{I} 6+0,095 \mathrm{NI}+0,0 \mathrm{I} 5 \mathrm{MODI} \pm 0, \mathrm{II} O & \mathrm{R}=0,90 \\
n=9 \text { ray-grass }+2 \text { fétuques } & \\
\mathrm{NR}=-0,233+0, \mathrm{I} 74 \mathrm{NI}+0,003 \text { MODI } \pm 0,074 & \mathrm{R}=0,82 \\
n=\mathrm{I} 2 \text { dactyles } &
\end{array}
$$

Si l'on prend comme exemple le ray-grass $n^{0} 4$ (tabl. I) avec MODI $=857$ et $\mathrm{NI}=30,3$, et le dactyle $\mathrm{n}^{\circ}$ Io avec $\mathrm{MODI}=864$ et $\mathrm{NI}=30,9$ (donc des valeurs très voisines pour les deux espèces) on trouve $\mathrm{NR}=0,36$ pour le ray-grass et $\mathrm{NR}=0,20$ pour le dactyle.

La prise en considération d'une troisième variable n'améliore plus la liaison, à l'exception de celle obtenue en associant à la quantité d'azote ingérée, la quantité de matière organique digestible ingérée et la teneur en glucides solubles.

La quantité d'azote retenue, exprimée en p. Ioo de l'azote ingéré dépend des mêmes critères que la quantité d'azote retenue, exprimée en $\mathrm{g} /$ jour, mais les liaisons sont généralement moins étroites.

La quantité d'azote retenue (NR en g par jour) dépend de la quantité de protéines, digestibles dans l'intestin, ingérée (P.D.I. (I) en g par jour) :

$$
\mathrm{NR}=-5,77+0,09 \mathrm{PDI} \pm 2, \mathrm{I} 6 \quad r=0,89 \quad n=35
$$

$\mathrm{Si}$ on exprime ces résultats en $\mathrm{g}$ par jour et par $\mathrm{kg}$ de poids métabolique pour comparer des moutons de poids différent :

$$
\mathrm{NR}=-0,32+0,09 \mathrm{PDI} \pm 0, \mathrm{I} 4 \quad r=0,8 \mathrm{I} \quad n=35
$$

\section{Concentration en azote ammoniacal du jus de rumen}

La concentration moyenne journalière en azote ammoniacal du jus de rumen $\left(\mathrm{N}-\mathrm{NH}_{3}\right)$ est très variable d'un fourrage à l'autre: de 33 à $332 \mathrm{\gamma} / \mathrm{ml}$. Elle est

(r) I a quantité de protéines digestibles dans l'intestin ou P.D.I. est estimée à partir :

- d'une part de la fraction de l'azote alimentaire qui n'est pas dégradée dans le rumen et qui est digérée dans l'intestin : ce sont les protéines digestibles dans l'intestin d'origine alimentaire ou PDIA qui sont calculées à partir de la quantité de matières azotées totales dans l'aliment (MAT), de la solubilité de celles-ci (S) et de la digestibilité vraie de ces protéines dans l'intestin qui est cstimée à 75 et 85 p. cent respectivement pour les graminées et les luzernes, suivant la formule :

PDIA g/kg de matière sèche $=0,65$ MAT $\mathrm{g} / \mathrm{kg}$ de matière sèche $\times \frac{\text { Ioo- } \mathrm{S}}{\text { Ioo }} \times$ digestibilité vraie;

- d'autre part de la fraction d'azote microbien qui est synthétisé dans le rumen dont la synthèse est limitée : soit par la quantité d'énergie disponible, ce sont les PDIME qui sont calculées d'après la formule :

PDIME, $\mathrm{g} / \mathrm{kg}$ de matière sèche $=75,6$ M.O.D. ou matière organique digestible en $\mathrm{kg} / \mathrm{kg}$ de matière seche, soit par la quantité d'azote fermentescible disponible, ce sont les PDIMN qui sont calculées d'après la formule :

PDIMN g/kg de matière sèche $=$ M.A.T. g/ $/ \mathrm{kg}$ de matière sèche $\times\left(0,196+0,364 \frac{\mathrm{s}}{100}\right)$

(JOURNET et V'́rité, I977) 
plus élevée pour lesluzernes que pour les graminées et elle diminue avec 1'âge du fourrage. Elle augmente en effet en même temps que la teneur en azote des fourrages (tabl. 5), la quantité d'azote total ou d'azote soluble ingérée, ou mieux encore, les rapports entre la quantité d'azote total ou d'azote soluble ingérée et la quantité de matière organique digestible ingérée. Elle est liée négativement à la teneur en glucides solubles.

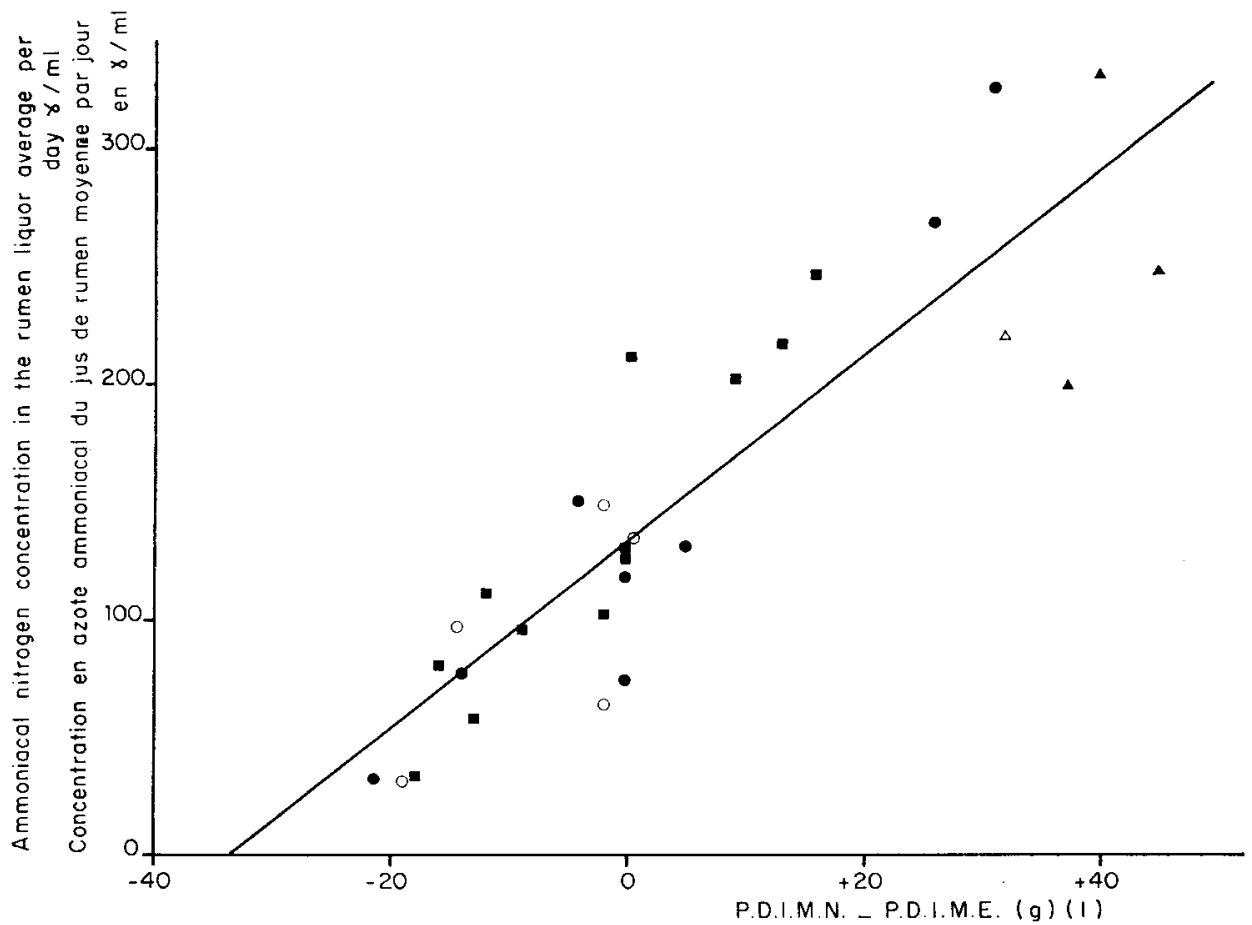

FIG. 3. - Relation entve la concentration en azote ammoniacal du jus de rumen et la différence PDIMN et PDIME en $g$

Relationship between ammoniacal nitrogen concentration in the rumen liquor and the difference $P D I M N-P D I M E g$ (PDIMN: protein truly digestible in the small intestine coming from microbial synthesis allowed by fermentable nitrogen and PDIME : protein truly digestible in the small intestine coming from microbial synthesis allowed by energy).
$\nabla$ Luzerne
$\Delta+$ Orge
- Ray-grass
$\mathrm{O}+$ Orge
$\mathrm{O}+$ Barley
- Dactyle
$\triangle+$ Barley
- Rye-grass
- Cocksfoot

(p)

Fille augmente avec la différence PDIMN - PDIME (p. 24) (fig. 3) comme suit :

$$
\mathrm{N}-\mathrm{NH}_{3}=\mathrm{I} 33, \mathrm{I} 7+3,95(\text { PDIMN-PDIME }) \pm 40,40 \quad r=0,88 \quad n=29 .
$$

La quantité d'azote excrétée dans l'urine est liée positivement à la concentration moyenne en azote ammoniacal du jus de rumen ou à la différence entre la concentration maximale ( $\mathrm{T}$ max.) atteinte après le repas et la concentration initiale mesurée avant le repas (To), soit $\mathrm{T} \max$ - To.

L'augmentation de fertilisation azotée de 33,5 à roo unités d'azote à l'hectare modifie peu la concentration en azote ammoniacal du jus de rumen (tab1. 2). De même, cette dernière est en moyenne inchangée par la complémentation avec l'orge (tabl. 3). 


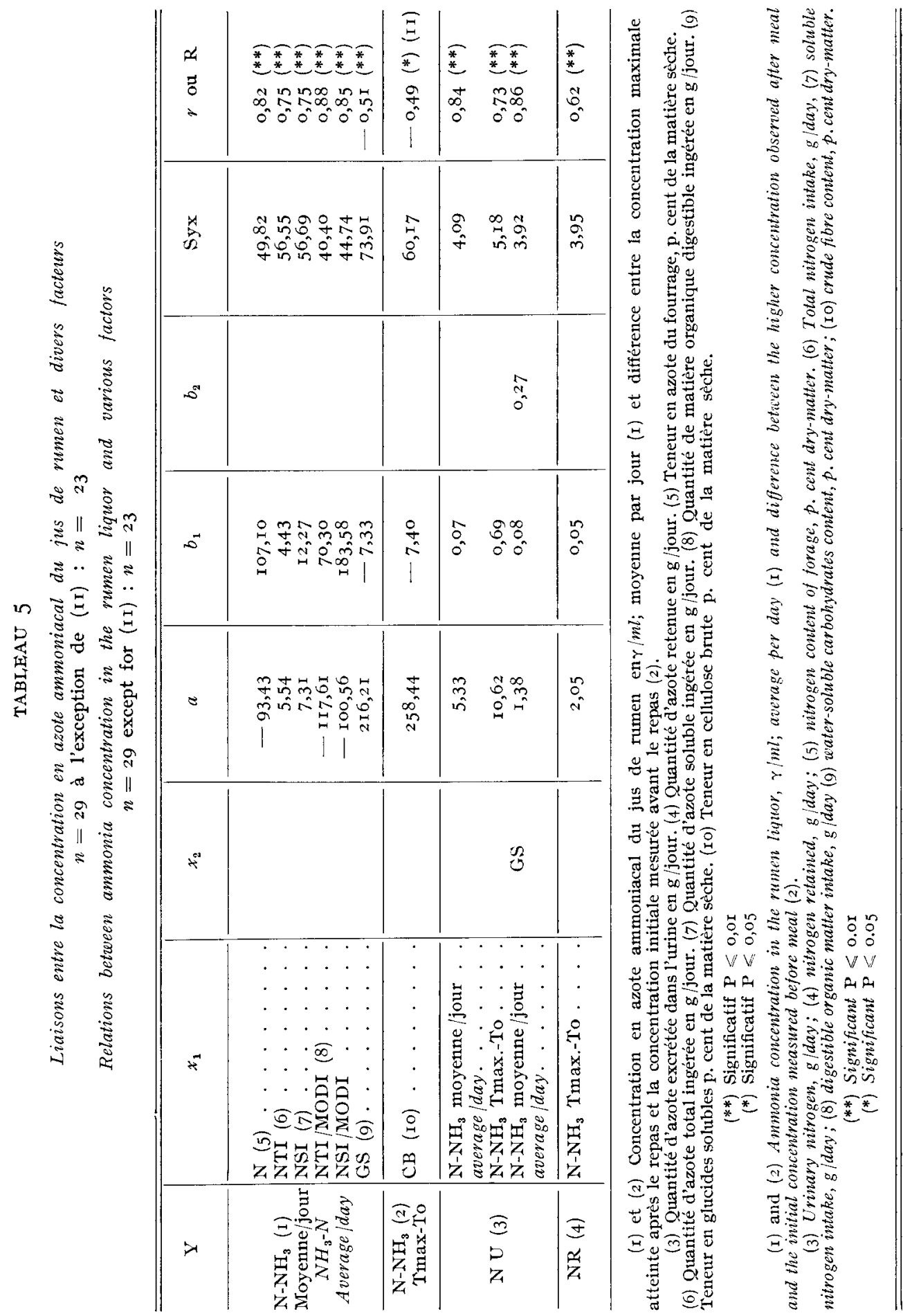




\section{Discussion}

Nos résultats montrent que la quantité d'azote retenue par les moutons peut varier considérablement suivant le fourrage qu'ils ingèrent; avec du dactyle au stade floraison les moutons perdent $0,5 \mathrm{~g}$ d'azote par jour tandis qu'à l'opposé avec de la luzerne ou du ray-grass jeunes ils retiennent jusqu'à ro ou $\mathbf{5} \mathrm{g}$ d'azote par jour. La quantité d'azote retenue est d'autant plus élevée que les quantités d'azote et de matière organique digestible ingérées sont importantes. Les synthèses microbiennes dans le rumen ont besoin à la fois d'énergie, apportée par la matière organique digestible, et d'azote pour être efficaces. On peut estimer d'après le calcul des PDI quelle est la part, dans l'azote arrivant au niveau du duodénum, qui provient de l'azote alimentaire et quelle est celle qui provient de l'énergie, c'est-à-dire 1'azote microbien. C'est ainsi que pour une luzerne de premier cycle, de digestibilité de la matière organique $63,4 \mathrm{p}$. Ioo et renfermant I $8,6 \mathrm{p}$. Ioo de matières azotées (échantillon $n^{\circ}$ I, tabl. I) 5 I p. Ioo de l'azote arrivant dans le duodénum est d'origine alimentaire et $49 \mathrm{p}$. Ioo d'origine microbienne, et pour un ray-grass italien de digestibilité de la matière organique $74,4 \mathrm{p}$. Ioo et renfermant I3,9 p. Ioo de matières azotées (échantillon $\mathrm{n}^{0} 4$ ) 44,5 p. Ioo de l'azote arrivant dans le duodénum est d'origine alimentaire et $55,5 \mathrm{p}$. Ioo d'origine microbienne. Ces proportions respectives d'azote d'origine alimentaire et microbien sont très voisines de celles mesurées par UlyatT et al. (I975) sur des fourrages verts. D'après nos calculs la quantité d'azote retenue augmente linéairement avec la quantité de PDI ingérée, ce qui prouve ainsi qu'il existe un bon synchronisme chez le mouton en croissance recevant de l'herbe verte entre les quantités de protéines et d'énergie absorbées. En effet, il n'est pas suffisant pour que la quantité d'azote retenue soit élevée, que la quantité d'acides aminés absorbée au niveau de l'intestin le soit, encore faut-il que l'énergie absorbée soit suffisante pour fixer ces acides aminés (BLACK et GRIFFiTHS, I975).

La quantité d'azote retenue dépend aussi de la digestibilité de la matière crganique du fourrage vert et cela vraisemblablement parce que cette dernière est un bon critère non seulement de la quantité de matière organique digestible ingérée mais aussi de la vitesse de dégradation de cette matière organique dans le rumen. L'énergie des membranes est libérée plus ou moins vite suivant leur degré de lignification. La quantité d'azote retenue est liée négativement à la teneur en cellulose brute des fourrages. La relation est plus étroite qu'avec la digestibilité de la matière organique notamment quand on considère l'ensemble des graminées et des luzernes pour lesquelles la liaison avec la digestibilité n'est pas significative. Pour une même teneur en cellulose brute les luzernes sont en effet moins digestibles que les graminées mais elle sont digérées beaucoup plus rapidement (DEMARQuiLLY et Chenost, ig69, Demarquiliy et Jarrige, I973).

Pour une même quantité d'azote et de matière organique digestible ingérée nous avons vu que la quantité d'azote retenue était bien supérieure pour les moutons alimentés avec des ray-grass que pour ceux alimentés avec des dactyles. Or, on sait (JARRIGE et MINSON, I964) que la composition de la matière organique digestible de ces deux espèces est très différente. A stade de végétation comparable la matière organique digestible des ray-grass contient beaucoup plus de glucides solubles que celle des dactyles, mais moins de membranes digestibles. L'énergie fournie par les ray-grass est beaucoup plus rapidement disponible pour les synthèses microbiennes, grâce aux glucides solubles, que celle des dactyles et doit 
permettre une meilleure fixation de l'azote. Il est également possible que les matières azotées des dactyles soient plus fermentescibles dans le rumen que celles des ray-grass.

On sait que la concentration en acides gras volatils totaux du jus de rumen n'atteint souvent son maximum que 3 ou 4 heures après le début du repas alors que la concentration en azote ammoniacal atteint son maximum beaucoup plus rapidement. Ia libération d'énergie est donc souvent plus lente que la libération d'ammoniaque et il peut alors y avoir des "fuites " d'ammoniaque, notamment dans les toutes premières heures qui suivent le repas si la production d'ammoniaque est supérieure à la capacité de protéosynthèse des microorganismes du rumen. Cet azote en excès est excrété en partie dans l'urine et est donc perdu pour l'animal. On constate d'ailleurs qu'effectivement la quantité d'azote excrétée dans l'urine est d'autant plus élevée que la concentration en azote ammoniacal du jus de rumen est élevée. L'ammoniaque est d'autant mieux utilisée pour la prolifération microbienne que la digestion de la matière organique fournissant l'énergie nécessaire est elle-même rapide. On peut en voir comme preuve la liaison négative observée entre la teneur en azote ammoniacal du jus de rumen et la teneur en glucides solubles des fourrages, ces glucides constituant une source d'énergie immédiatement disponible pour les microorganismes du rumen.

En revanche, le fait qu'avec des fourrages pour lesquels la différence PDIMNPDIME est inférieure à o (fig. 3) on trouve encore de l'azote ammoniacal dans le jus de rumen traduit l'existence d'un recyclage important de l'ammoniaque au niveau du rumen. Sinon, en effet, lorsque la quantité d'azote fermentescible est plus faible que la quantité d'énergie disponible la concentration en azote ammoniacal du jus de rumen devrait être pratiquement nulle.

L'apport d'orge avec les fourrages verts a entraîné une augmentation de 1'excrétion d'azote dans les fèces, mais pas de variation significative de l'excrétion d'azote urinaire ni de la rétention azotée. En revanche, DU PLEssis et MERVE (r969) ont obtenu une augmentation de la rétention azotée en ajoutant de l'amidon ou de la farine de maîs à du fourrage vert de légumineuses. Pour les fourrages verts que nous avons étudiés et qui sont en moyenne très digestibles la quantité d'azote retenue est déjà très importante avec les fourrages distribués seuls, parce que la synthèse protéique microbienne est grande, et l'apport d'orge qui n'augmente pas la quantité de matière organique digestible ingérée ni la digestibilité, donc vraisemblablement pas la vitesse de digestion, a dû peu augmenter la synthèse protéique microbienne dans le rumen. Cela serait d'ailleurs confirmé par le fait que l'apport d'orge n'a pas fait diminuer la teneur en azote ammoniacal du jus de rumen.

L'apport d'orge n'a pas augmenté la digestibilité de la matière organique de la ration totale vraisemblablement parce qu'il a diminué la digestibilité des membranes du fourrage dans le rumen. Le contenu digestif arrivant au niveau du gros intestin doit donc renfermer davantage d'énergie que lorsque les fourrages sont distribués set1ls par suite de la présence de membranes non dégradées. Cette énergie doit permettre la fixation d'urée recyclée au niveau du caecum. L'azote fécal est alors accru de l'azote des microorganismes ainsi formés (ORskov et al., I970).

Dans nos résultats, la quantité d'azote retenue a été diminuée par la fertilisation azotée par suite d'une perte accrue d'azote par la voie urinaire. Le rapport azote ingéré sur matière organique digestible ingérée est un peu augmenté par la fertilisation azotée. Dans la mesure où celle-ci modifie peu la digestibilité de la matière organique et par là vraisemblablement la vitesse de digestion, qu'elle 
n'augmente pas la quantité de matière organique digestible ingérée et qu'elle diminue la teneur en glucides solubles, il n'est pas étonnant qu'elle n'améliore pas la rétention azotée. HoGAN et WEs'ron (I969) avec de l'avoine sur pied, et BEEVER et THOMSON (I973) avec du ray-grass anglais, ont montré que la quantité d'azote arrivant dans le duodénum était même diminuée par la fertilisation azotée.

En conclusion, les bilans azotés, et donc les croîts les plus élevés sont obtenus soit avec des graminées jeunes et digestibles, très riches en glucides solubles, soit avec des luzernes, moins digestibles, mais qui sont ingérées en très grandes quantités et digérées très rapidement.

Par ailleurs, la distribution d'orge avec les fourrages jeunes présente un faible intérêt du point de vue nutritionnel.

Accepté pour publication en juillet 1977.

\author{
Summary \\ Utilization of fresh herbage nitrogen by growing sheep: \\ infuence of herbage growth stage, herbage species, nitrogen fertilization \\ and barley supplementation
}

Io Thirty-five fresh herbage samples were used in this study: lucerne, Italian rye-grass, perennial rye-grass, tall fescue, and cocksfoot harvested at different $\mathrm{I}^{\mathrm{st}}$ growth stages and at various regrowth ages. The $3^{\text {rd }}$ grow th of cocksfoot corresponded to 2 nitrogen fertilization levels.

Twenty-nine herbage samples were offered alone and six, either alone or with barley representing in each case 23 per cent of the total dry matter intake.

The herbages were given ad libitum (Io per cent refusals). Digestibility, ingestibility and nitrogen balance were measured on groups of 6 castrated male sheep, about 12 months old and weighing $50 \mathrm{~kg}$, on an average. Pre-experimental periods lasted 3 weeks and periods of measurements 6 days. The sheep received 2 meals per day ad libitum. The grass required for the animals was cut every morning, except lucerne $n^{\circ}$ I (Table I) which was frozen. Barley was offered in two equal meals before each fresh herbage feeding.

Rumen liquor was taken from 2 supplementary sheep fitted with a rumen fistula, just before the morning meal, then $r, 2,3,4,6$ and 8 hours thereafter and for 2 consecutive days at each period of measurement.

$2^{0}$ The results of the measurements are given in tables I and 2. The amount of nitrogen retained $(Y)$ varied from -0.5 to $+16.2 \mathrm{~g}$ per day. It was closely related with the amount of nitrogen ingested ( $x i$ in $\mathrm{g}$ per day):

$$
\mathrm{x}=-4.25+0.30 x i \pm 2,23 \quad v=0,89 \quad n=26
$$

(Table 2).

Nitrogen fertilization reduced nitrogen retention from 2.77 to $0.10 \mathrm{~g}$ per day, on an average

$3^{\circ}$ Barley offered together with fresh herbages had a variable effect on the organic matter digestibility of the ration (Fig. I). The latter was not increased in the case of forages with a high digestibility $\left(>7^{\circ}\right.$ per cent) whereas an increase was observed when the digestibility of the forages was lower than 70 per cent. Relations between urinary and fecal N-excretion or $\mathrm{N}$-retention, on the one hand, and $\mathrm{N}$ intake expressed in g per day, on the other, for herbages alone or for herbages + barley are given in figure 2. Nitrogen retention was not significant by changed by the addition of barley.

$4^{\circ}$ Nitrogen retention in $g$ per day increased with the digestible organic matter intake and the digestibility of the forages. It decreased with increasing crude fibre content (Table 4 ). On the basis of nitrogen and digestible organic matter intakes the amount of nitrogen retained by the sheep can be accurately forecasted $(r=0.88$ or 0.90 , table 4$)$.

However, there were differences between the plant species: for the same nitrogen and digestible organic matter intake, rye-grass led to a higher N-retention than cocksfoot.

Nitrogen retention ( $\mathrm{NR}$ in $\mathrm{g}$ per day) increased with the amount of P.D.I. (I) ingested (in g per day):

(I) P.D.I. $=$ protein truly digestible in the small intestine. 


$$
\mathrm{NR}=-5,77+0.09 \text { P.D.I. } \pm 2.16 \quad r=0.89 \quad n=35
$$

$5^{\circ}$ The daily average concentration of ammonia nitrogen in the rumen liquor was highly variable: from 33 to $332 \% / \mathrm{ml}$. It increased with the nitrogen intake. The urinary $\mathrm{N}$-excretion was positively correlated with this daily average concentration or with the difference of concentration $T$ max.-To ( $T$ max is the maximum concentration reached after the meal and To the initial concentration measured before the meal).

$6^{\circ}$ The influence of the nitrogen and digestible organic matter intake, with fresh herbages, on the microbial syntheses in the rumen and on the quantity of nitrogen reaching the duodenum as well as on the quantity of nitrogen retained, is discussed. The differences observed between herbage species might be explained by differences in digestion rates, on the one hand, and in digestible organic matter compositions, on the other.

The little interest of feeding barley as a supplement to fresh herbages offered ad libitum, is discussed.

\section{Références bibliographiques}

BeEver D. E. et Thomson D. J., 1973. Résultats cités par D. G. Armstrong : Factors affecting the protein value of fresh and conserved feeds. Proc. 5 th general meeting, European Grassland Federation. Uppsala. June r973. Main papers II4-I22.

BLACK J. L. et GRIFFITHS D. A., I975. Effects of live weight and energy intake on nitrogen balance and total $\mathrm{N}$ requirement of lambs. Br.J. Nutr., 33, 399-4I3.

CAMERON C. D. T., r966. The effects of nitrogen fertilizer application rates to grass on forage yields, body weight gains, feed utilization, and vitamin A status of steers. Can. J. Anim. Sci., 46, I9-24.

Chalmers Margaret I. et Synge R. L. M., I954. The digestion of protein and nitrogenous compounds in ruminants. Adv. Protein Chem., 9, 93-I 20.

DEMARquil y C. et Chenost M., ig69. Étude de la digestion des fourrages dans le rumen par la méthode des sachets de nylon. Liaisons avec la valeur alimentaire. Ann. Zootech., 18, 4I9-436.

DEMARQUilLy C., I970. Influence de la fertilisation azotée sur la valeur alimentaire des fourrages verts. Ann. Zootech., 19, 423-437.

DeMARQUIL, Y C. WEISS Ph., I970. Tableaux de la valeur alimentaire des fourvages. INRA -E.tude du S.E.I. $n^{0} 4^{2}$, Paris.

DEMARQUILLY C. JARRIGE R., I973. The comparative nutritive value of grasses and legumes. Proc. 5 th General meeting, European Grassland Federation. Uppsala - June r973. Main papers $33-4 \mathrm{I}$.

DU PLESSIS G. F. et VAN DFR MERVE F. J., I969. The effect of carbohydrate supplementation on the nitrogen balances of sheep fed fresh frozen clover and lucerne. A groanimalia, 1, I 55-I6o.

Hogan J. P. et WESTON R. H., I969. The digestion of pasture plants by sheep. III. The digestion of forage oats varying in maturity and in the content of protein and soluble carbohydrate. Aust. I. Agric. Res., 20, 347-363.

HUGUET I. et GILIET M., I973. The influence of nitrogen fertilizer and autumn management on the quality of green forages. Proc. 5 th General meeting, European Grassland Federation. Uppsala - June I973. Short reports. Ioo-I IO.

Hume I, D. et PUrser D. B., I974. Ruminal and post-ruminal protein digestion in sheep fed on subterranean clover harvested at four stages of maturity. Aust. J. A gric. Res., 26, I99-208.

Jarrige: R. Minson D. J., I964. Digestibilité des constituants du ray-grass anglais $\mathrm{S} 24$ et du dactyle $\$$ 37, plus spécialement des constituants glucidiques. Ann. Zootech., 13, II7-I 50.

JOURNET M. et VERITE R., 1977. Levels of energy and nitrogen intake in relation to animal protein production during lactation. 2na Inter. Symposium on protein metabolism and nutrition. E.A.A.P. Flevohof, Pays-Bas, mai 1977.

Jovce J. P. et NEWTH R. P., I967. Use of the comparative slaughter technique to estimate the nutritive value of pasture for hoggets. Proc. N. Z. Soc. Anim. Prod., 27, 166-I80.

Graham N. Mac, 1964. Utilization by fattening sheep of the energy and nitrogen in fresh herbage and in hay made from it. Aust. J. A gric. Res., 15, 974-981.

RAE J. C. Mac et UlYaT'T M. J., 1974. Quantitative digestion of fresh herbage by sheep. II. The sites of digestion of some nitrogenous constituants. J. Agric. Sci., 82, 309-3I9.

Nowakowski T. Z., I962. Effects of nitrogen, soluble nitrogen and soluble carbohydrate contents of grass. J. Agric. Sci., 59, 387-392. 
ØKSKOV I. R., FRASER C., MASON V. C. and MANN S. O., I970. Influence of starch digestion in the large intestine of sheep on caecal fermentation, caecal microflora and faecal nitrogen excretion. Br. J. Nutr., 24, 67 г -682.

RATTRAY P. V. JOYCE J. P., I969. The utilization of perennial rye grass and white clover by young sheep. Proc. N. Z. Soc. Anim. Prod., 29, Ioz-I I3.

RFid R. L., Jung G. A. et MurRay S. J., 1966. Nitrogen fertilization in relation to the palatability and nutritive value of orchard grass. $J$. Anim. Sci., 25, 636-645.

Somogyi S., 1952. Notes on sugar determination. J. Biol. Chem., 105, 19-23.

Ulyat' M. J., Mackae J. C., Clarke R. T. J. and Peakce P. D., I975. Quantitative digestion of fresh herbage by sheep. IV - Protein synthesis in the stomach. J. Agric. Sci., 84, 453-458.

WAITE R., I958. The water-soluble carbohydrates of grasses. IV. The effect of different levels of fertilizer treatment. J. Sci. Food Agric., 9, 39-43. 